\title{
Enteral feeding practices in preterm infants in South Africa
}

\author{
M S Raban, Y Joolay, A R Horn, M C Harrison \\ Department of Neonatology, Groote Schuur Hospital, Cape Town \\ M S Raban, MB ChB, FCPaed (SA), Cert Neonatol (SA), DCH (SA), DipHIVMan (SA) \\ Y Joolay, MB ChB, FCPaed (SA), Cert Neonatol (SA) \\ A R Horn, MB ChB, FCPaed (SA), Cert Neonatol (SA), DCH (SA) \\ M C Harrison MB ChB, MRCP, FRCPCH \\ Corresponding author: M S Raban (shukriraban@yahoo.co.uk)
}

\begin{abstract}
Background. Optimal feeding regimens in babies weighing < $1000 \mathrm{~g}$ have not been established, and wide variations occur. In South Africa (SA) this situation is complicated by varied resource constraints.

Objective. To determine the preterm enteral feeding practices of paediatricians in SA.

Methods. We invited 288 paediatricians to participate in a cross-sectional web-based survey.

Results. We received responses from $31.2 \%$ of the paediatricians; $43.6 \%$ were from the state sector and $56.4 \%$ from the private sector. Most participants worked in medium-sized neonatal units with $6-10$ beds. The proportions commencing feeds within the first 24 hours were $24 \%$ in infants of $<25$ weeks' gestational age, $36 \%$ in infants $25-27$ weeks, and $65 \%$ in infants $28-31$ weeks. Feed volumes were routinely advanced daily in $47 \%$ of infants $<25$ weeks, $68 \%$ of infants $25-27$ weeks, and $90 \%$ of infants $28-31$ weeks. Forty-five per cent of infants $<25$ weeks received continuous intragastric feeds, while $50 \%$ of those in the 28 - 31 weeks group were on 3-hourly bolus feeds. The majority of the participants targeted full enteral feeds of $161-180 \mathrm{ml} / \mathrm{kg} / \mathrm{d}, 66.7 \%$ had access to donor milk, and $77 \%$ used breastmilk fortifier. Conclusion. This is the first study to survey feeding practices in SA. The survey did not highlight differences in feeding practices among paediatricians. These data could be valuable in the design of local collaborative trials to determine optimal feeding strategies.
\end{abstract}

S Afr J CH 2013;7(1):8-12. DOI:10.7196/SAJCH.503

The optimal enteral feeding regimen for preterm infants has not been established, and remains particularly challenging in infants weighing less than $1000 \mathrm{~g} .{ }^{[1]}$ The debate on when to initiate feeds and speed of advancement of feed volumes is nuanced by studies raising concerns that early and rapid feeding strategies increase the risk of feeding intolerance and may be involved in the pathogenesis of necrotising enterocolitis (NEC) ${ }^{[2-4]}$ although causality has not been proven..$^{[2,4,5]}$

International enteral feeding practices for preterm infants have been surveyed in previous studies. Hans et al. surveyed practices in North America, Tuthill in the UK and Eire, and Patole and Muller in Australia. ${ }^{[6-8]}$ Most recently, Klingenberg et al. surveyed 127 tertiary neonatal units in Australia, Canada, Denmark, Ireland, New Zealand, Norway, Sweden and the UK. ${ }^{[9]}$ These surveys highlighted a wide variation in enteral feeding practices among paediatricians.

South Africa (SA) comprises a mix of developed and developing health systems, which results in wide variations of resource constraints. A wide variation exists between the private sector and the resourceconstrained public sector, which potentially influences clinical care. Preterm feeding practices have not yet been surveyed in this country, and our article may inform the design of local collaborative trials to determine optimal preterm infant feeding strategies.

\section{Methods}

The study was a cross-sectional survey of paediatricians working in SA state and private hospitals that had neonatal intensive care units (NICUs). The research was approved by the University of Cape Town Faculty of Health Sciences Human Research Ethics Committee.
Potential participants were identified from an online listing of 147 NICUs in hospitals across SA on the Medpages directory website. ${ }^{[10]}$ The names and contact details of 320 paediatricians working in those units were obtained by searching the websites of the respective hospitals. In addition we used an e-mail database compiled for a previous web-based survey completed in our unit. ${ }^{[1]}$ Doctors who did not treat neonates in their practice were excluded. Practitioners did not receive incentives to participate.

The survey questionnaire was created and hosted using Survey Monkey, an online survey website. An e-mail containing an individualised link to the survey was sent to 288 paediatricians on 30 September 2011. The Survey Monkey collector tool collected all responses anonymously and automatically sent reminder e-mails to those who had not yet responded. Survey collection closed on 30 November 2011.

With Claus Klingenberg's permission, we modified the questionnaire he used in his international survey of enteral feeding practices. ${ }^{[9]}$ The questionnaire, consisting of multiple-choice and open-ended questions, requested information about the demographics of the unit, the presence of a milk bank or access to donor breastmilk, initiation and advancement of enteral feeds, indications for and use of breastmilk fortifier, supplementation with oral vitamins, and feeding strategies after discharge.

\section{Data analysis}

Responses were exported to a Microsoft Excel file. Data were analysed with Stata version 11 (Stata Corporation, College Station, USA). Chi-square and Fisher's exact tests were used for comparison of categorical variables. Descriptive results were expressed as 
numbers and proportions (\%). A $p$-value of $<0.05$ was considered significant.

\section{Results}

We received responses to 78 of 288 emails sent (31.2\% response rate). The demographics of the individuals surveyed are shown in Table 1 . Of the responses, 34 $(43.6 \%)$ were received from the state sector and $44(56.4 \%)$ from the private sector. Most of the participants $(42 / 78,53.8 \%)$ worked in medium-sized neonatal units with 6 - 10 beds (state sector 20/34 (58.8\%), private sector $22 / 44(50.0 \%))$.

Two-thirds of participants had access to donor human milk, with relatively equal distribution between the private and state sectors.

The timing of feed commencement in the different gestational age (GA)/weight categories is illustrated in Fig. 1. Most preterm infants were commenced on enteral feeds within the first 48 hours after birth. The rate of enteral feeding in the first 24 hours was lower in the more preterm infants, whereas $65 \%$ of infants of 28 - 31 weeks' GA received feeds within 24 hours.

Feed advancement strategies are illustrated in Fig. 2. Trophic feeds (minimal enteral feeds) were defined as feeding with small volumes, i.e. $0.5-1 \mathrm{ml} / \mathrm{kg}$ up to a maximum of $20 \mathrm{ml} / \mathrm{kg} / \mathrm{d}$, with this volume being maintained for 4 - 5 days before increasing feeds on a daily basis. Feeding practices in infants $<25$ weeks $(<700 \mathrm{~g})$ were evenly split between receiving trophic feeds or increased daily increments. The majority of infants $>25$ weeks $(>700 \mathrm{~g})$ had their feeds increased daily rather than trophic feeds.

Almost half of infants $<25$ weeks $(<700 \mathrm{~g})$ received continuous infusion of milk feeds via an intragastric tube. Responses in the $25-27$ weeks $(<1000 \mathrm{~g})$ group were very similar for continuous infusion and 2-hourly and 3-hourly bolus feeds; $50 \%$ of respondents chose 3-hourly bolus feeds as the feeding interval of choice in the $28-31$ weeks ( $<1500 \mathrm{~g}$ ) group. (Fig. 3).

Most respondents (57\%) targeted an enteral volume of $161-180 \mathrm{ml} / \mathrm{kg}$ (Fig. 4).

The two commonest causes for delaying the initiation of feeds were unavailability of human breastmilk and perinatal asphyxia (Fig. 5).

Breastmilk fortifier was routinely prescribed by more than $75 \%$ of the participants (Fig. 6).

A subgroup analysis comparing all the feeding practices surveyed between public and private institutions revealed no statistically significant differences.

\section{Table 1. Demographics of neonatal units surveyed $(N=78)$}

\begin{tabular}{ll}
\hline Nature of practice, $n(\%)$ & \\
Private health sector & $44(56.4)$ \\
Public health sector & $34(43.6)$ \\
ICU beds, $n(\%)$ & \\
$1-5$ & $24(30.8)$ \\
$6-10$ & $42(53.8)$ \\
$>10$ & $12(15.4)$ \\
Access to donor milk, $n(\%)$ & \\
Yes & $52(66.7)$ \\
No & $26(33.3)$
\end{tabular}

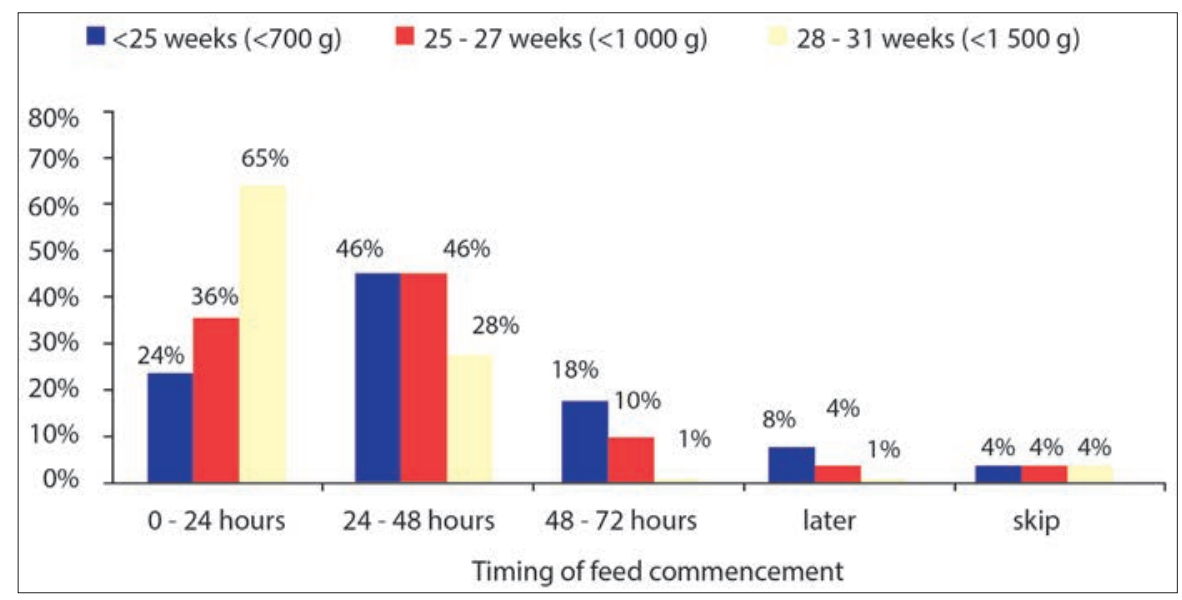

Fig. 1. Timing of feed commencement in different gestational age/weight categories.

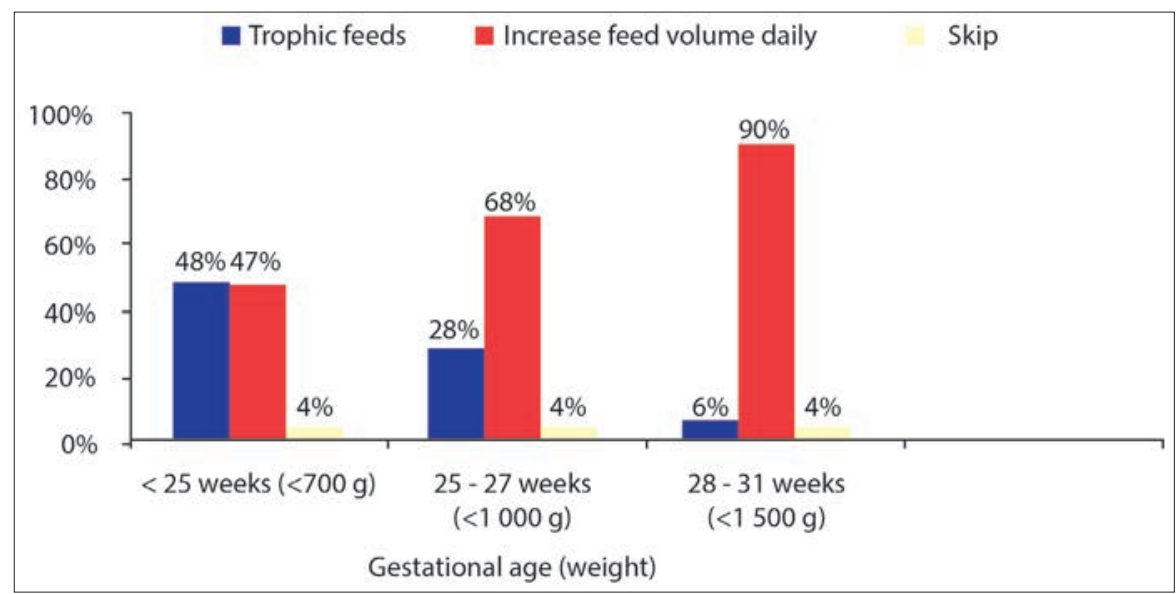

Fig. 2. Feed advancement strategies.

\section{Discussion}

SA's ability to achieve World Health Organization Millennium Development Goal 4 of reducing under-5 mortality is proving to be doubtful. The statistics for 2008 indicate that $29 \%$ of these deaths are attributable to neonatal causes. Of these deaths, $41 \%$ are due to prematurity and $23 \%$ to asphyxia, while $18 \%$ are related to infection. ${ }^{[12]}$ Bradshaw et al. demonstrate a decreasing trend in under-5 mortality from $56 / 1000$ in 2009 to $42 / 1000$ in 2011. ${ }^{[13]}$ However, South Africa remains one of 64 priority countries identified by the
Countdown to 2015 Initiative. ${ }^{[12]}$ Significant disparity exists within the SA health system. Private sector institutions are offering FirstWorld medicine in a developing country. In contrast, the state sector facilities that serve the greater community are resourceconstrained.

Improving neonatal care, in particular infant nutrition and the promotion of breastfeeding, is critically important in reducing neonatal deaths. Nutritional support in preterm infants, especially those of extremely low birth weight, is 


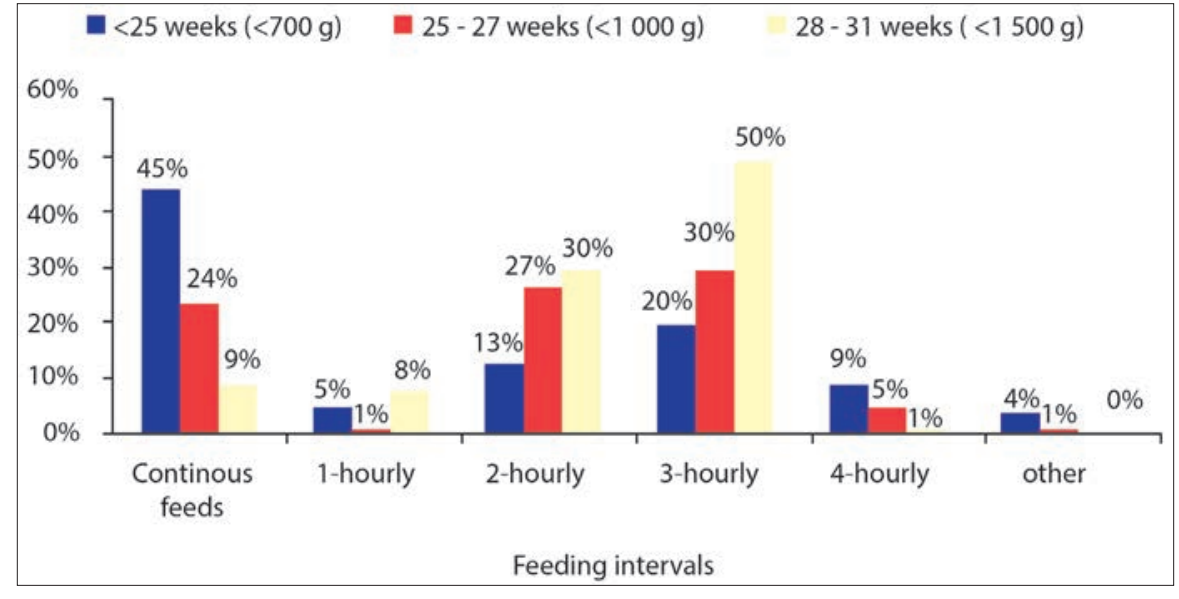

Fig. 3. Feeding intervals.

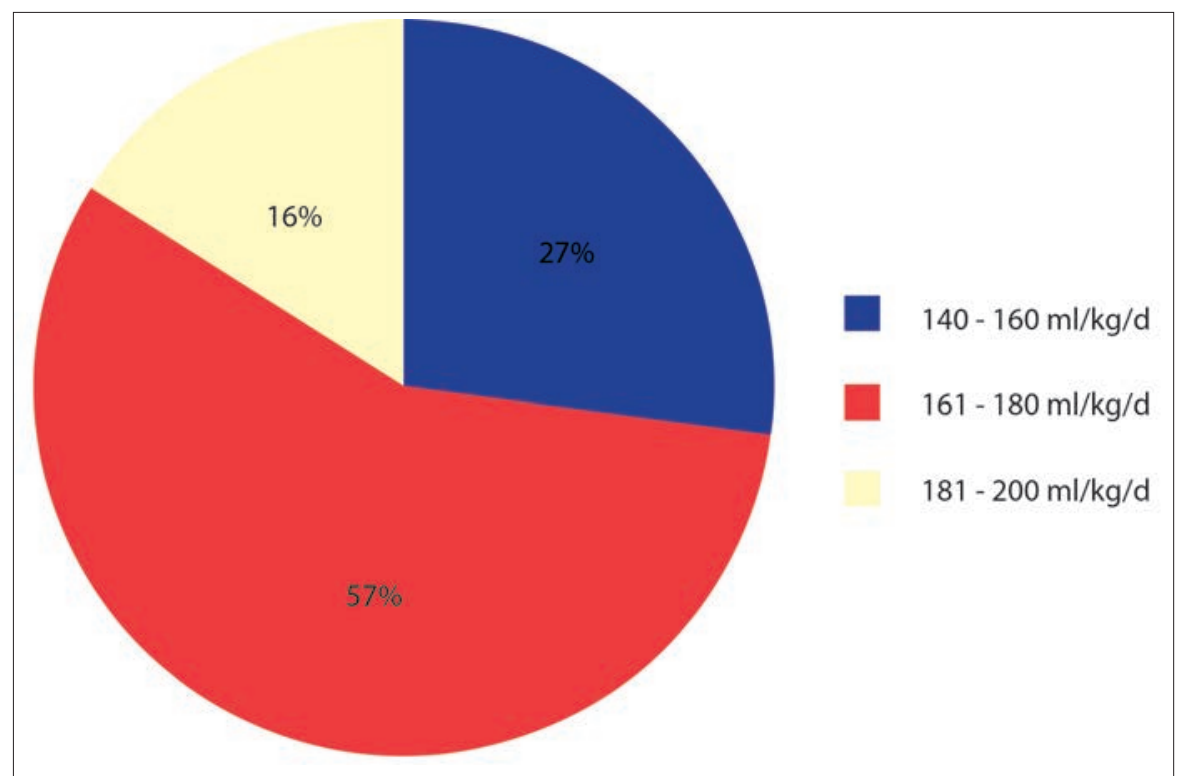

Fig. 4. Target enteral volume $(\mathrm{ml} / \mathrm{kg} / \mathrm{d})$.

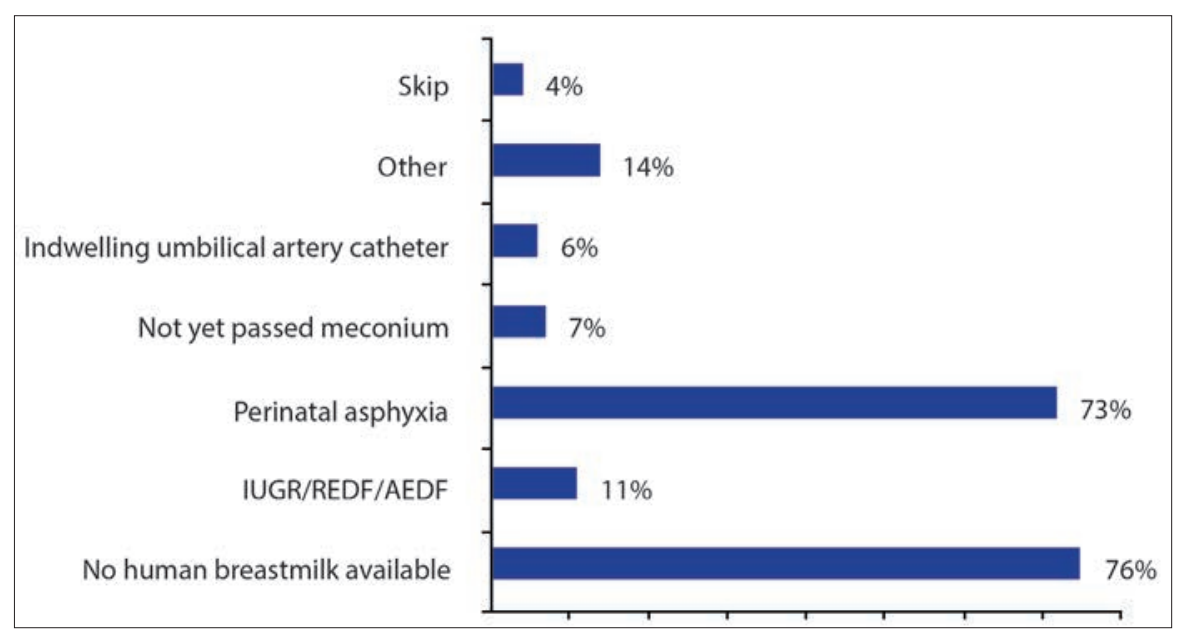

Fig. 5. Reasons for delaying onset of feeds (IUGR = intra-uterine growth retardation; REDF and AEDF = reversed or absent end-diastolic flow in the umbilical artery).

challenging with regard to both earlyoptimal growth and later neurodevelopmental outcomes. ${ }^{[14-16]}$ Studies to date in preterm infants have demonstrated that either poor or rapid growth is associated with unfavourable outcomes, but have not yet early or late, to use low or high volumes, and to advance feeds slowly or more rapidly.

The most common reason for delayed initiation and limited advancement of enteral feeds in immature infants is concern about increasing the risk of NEC. Delayed establishment of full enteral nutrition may lead to suboptimal growth ${ }^{[17]}$ and has been associated with neurodevelopmental delay at 18 - 22 months. ${ }^{[18]}$ A recent Cochrane review concluded that delaying the onset of enteral nutrition did not reduce the incidence of NEC. ${ }^{[19]}$ Additionally, infants on slow advancement strategies require long-term nutritional support in the form of parenteral nutrition. It is encouraging to note that the participants in our survey initiated feeds within the first 48 hours, and the unavailability of breastmilk may have played a role when feeds were not commenced in the first 24 hours. Randomised controlled trials as well as the Cochrane metaanalysis suggest that rapid advancement of feeds in increments of between $30-35$ $\mathrm{ml} / \mathrm{kg} / \mathrm{d}$ is safe with no increase in the risk of NEC. ${ }^{[1,19,21-24]}$ Although we did not specifically ask participants what volume they used to increase feeds daily, it is worth noting that they preferred to increase feeds daily as opposed to using trophic feeds. This is encouraging, as the Cochrane review concluded that trophic feeds did not reduce the incidence of NEC or improve outcomes. ${ }^{[25]}$

Preterm infants require higher protein intakes than term infants to attain adequate growth rates, and have relatively higher rates of protein turnover. ${ }^{[26,27]}$ The guidelines of the European Society of Paediatric Gastroenterology, Hepatology and Nutrition Committee (ESPGHAN) recommend enteral protein intakes of 4.0 - $4.5 \mathrm{~g} / \mathrm{kg} / \mathrm{d}$ for infants of less than 1000 $\mathrm{g}$ and $3.5-4.0 \mathrm{~g} / \mathrm{kg} / \mathrm{d}$ for those weighing $1000-1800$ g. ${ }^{[28]}$ After the first $3-4$ weeks, the protein content of expressed breastmilk is $\sim 1.1-1.3 \mathrm{~g} / 100 \mathrm{ml} .^{[9]}$ To meet protein demands, a minimum enteral volume of $180 \mathrm{ml} / \mathrm{kg} / \mathrm{d}$ and human breastmilk fortifier are therefore needed. Of participants in our study, 20\% did not routinely use breastmilk fortifier and the majority targeted an enteral volume of 161 - $180 \mathrm{ml} / \mathrm{kg} / \mathrm{d}$, thus in some instances not meeting protein requirement. Fortification of human milk is associated a with shortterm increase in weight gain and linear and head growth, and there is no evidence to support short-term deleterious effects. ${ }^{[29]}$ Doege et al. demonstrated that highvolume intake of fortified mother's milk at $200 \mathrm{ml} / \mathrm{kg}$ in infants of $<28$ weeks' GA was well tolerated, and these infants attained weight gain comparable to intra-uterine rates. ${ }^{[30]}$ 


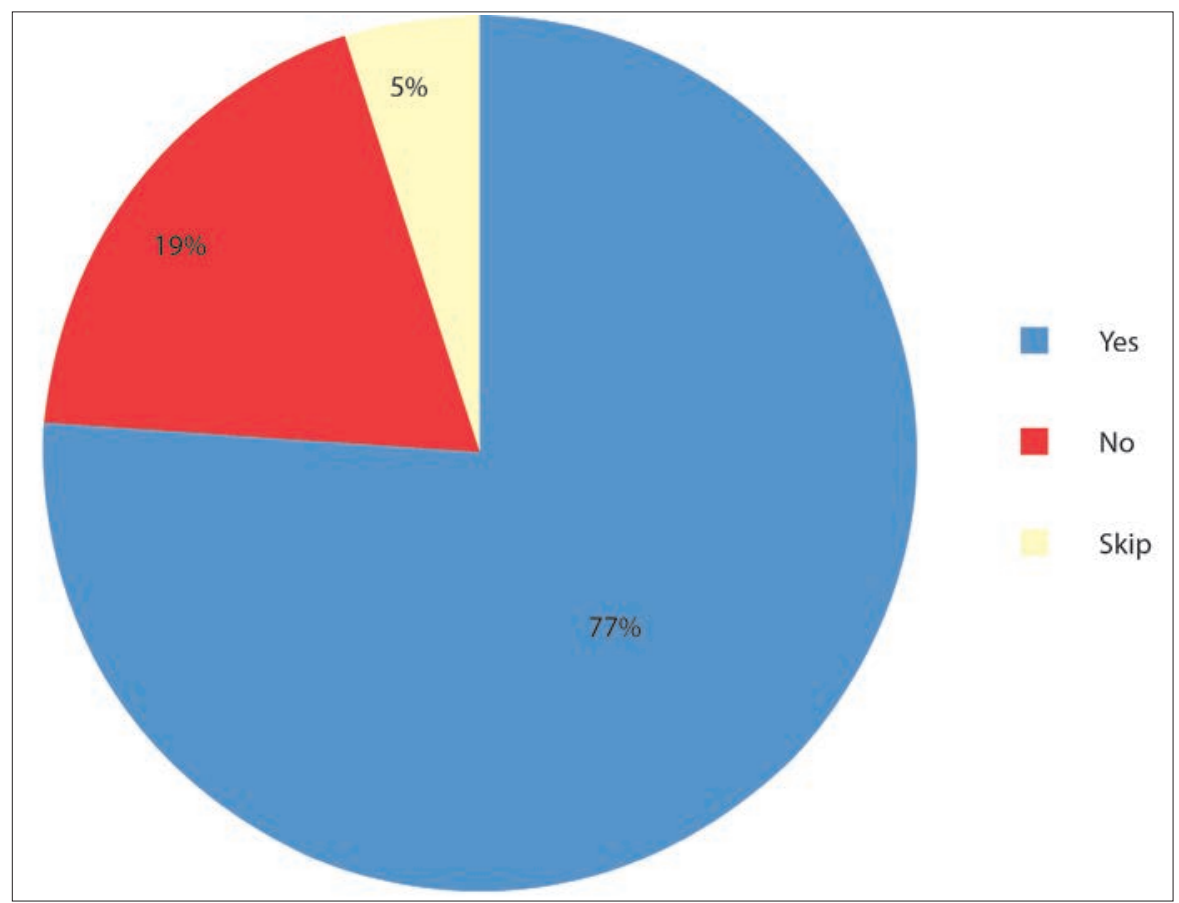

Fig. 6. Use of breastmilk fortifier.

Mothers of preterm infants have difficulty initiating lactation. ${ }^{[31]}$ A Cochrane review comparing formula-fed versus donor breastmilk-fed infants found a higher rate of short-term growth but also a higher risk of developing NEC in the formula-fed group. ${ }^{[32]}$ Donor breastmilk is pivotal in early feeding strategies. Despite two-thirds of units in our study having access to donor breastmilk, a common reason for delaying onset of feeds is unavailability of breastmilk. This may be due to low donor numbers, increased demand on a limited resource, and financial constraints on both non-governmental organisationfunded milk banks and public sector hospitals. Breastfeeding and breastmilk banks need greater promotion, utilisation and governmental support.

There are a few potential limitations to the data presented in this survey. The survey asked for the policies or strategies of feeding, but did not describe the actual enteral nutrition received; the data therefore reflect overall intent as opposed to specific intakes. Literature reviewing feeding practices in the past few years, by Cochrane in particular, may have induced bias, as the participants who completed the survey had a good knowledge base. Responses may therefore reflect views and opinions in the recent literature and not the actual feeding strategies employed by the individuals surveyed.

The survey was also limited by the relatively low response rate. SA doctors respond poorly to mail surveys, but Internet penetration is high, which is why we decided to conduct a web-based survey. ${ }^{[11,33]}$ Despite this, the response rate of $31.2 \%$ is lower than rates in the USA and Europe; however, it is higher than in a previous cross-sectional survey of paediatricians and neonatologists, ${ }^{[6,7,34]}$ where less than a quarter of polled physicians responded. It is also lower than in a recently conducted hypothermia web survey ${ }^{[11]}$ completed at our unit using a similar methodology. The latter survey reported a 37\% response rate, which was attributed to pre-contacting of clinicians by telephone, reminder e-mails for those who had not responded, and incentivising participants.

\section{Conclusion}

This is the first study to survey preterm feeding practices among paediatricians in SA. The findings illustrate that similar practices are followed by paediatricians working in the state and private sectors.

The need for research examining different feeding strategies to optimise early infant nutrition and ensure optimal longterm growth and development remains imperative. The findings of this study could be used to design local collaborative trials to determine optimal feeding strategies.

Acknowledgements. The authors thank all the participants who provided data for this survey, and Claus Klingenberg for allowing us to use the questionnaire similar to the one used in his international survey.

\section{Competing interests. None.}

\section{References}

1. Kennedy KA, Tyson JE. Rapid versus slow rate advancement of feedings for promoting growth and preventing necrotizing enterocolitis in parenterally fed low-birth-weight infants.
Cochrane Database of Systematic Reviews 1998, Issue 4. Art. No.: CD001241. [http://dx.doi. org/10.1002/14651858.CD001241]

2. Anderson DM, Kliegman RM. The relationship of neonatal alimentation practices to the occurrence of endemic necrotizing enterocolitis. Am J Perinatol 1991;8(1):62-67. [http://dx.doi. org/10.1055/s-2007-999344]

3. Berseth CL, Bisquera JA, Paje VU. Prolonging small feeding volumes early in life decreases the incidence of necrotizing enterocolitis in very low birth weight infants. Pediatrics 2003;111:529534. [http://dx.doi.org/10.1542/peds.111.3.529]

4. McKeown RE, Marsh TD, Amarnath U. Role of delayed feeding and of feeding increments in necrotizing enterocolitis. J Pediatr 1992;121:764-770. [http://dx.doi.org/10.1016/ s0022-3476(05)81913-4]

5. Book LS, Herbst JJ, Jung AL. Comparison of fast and slow feeding rates schedules to the development of necrotizing enterocolitis. J Pediatr 1976;89:463-466. [http://dx.doi. org/10.1016/s0022-3476(76)80552-5]

6. Hans DM, Pylipow M, Long JD, Thureen PJ, Georgieff MK. Nutritional practices in the neonatal intensive care unit: Analysis of a 2006 neonatal nutrition survey. Pediatrics 2009;123:5157. [http://dx.doi.org/10.1542/peds.2007-3644]

7. Tuthill DP. A survey of neonatal nutrition policies and practices in the UK and Eire. Maternal and Child Nutrition 2007;3:120-128. [http://dx.doi. org/10.1111/j.1740-8709.2007.00087.x]

8. Patole S, Muller R. Enteral feeding of preterm neonates: a survey of Australian neonatologists. Journal of Maternal-Fetal and Neonatal Medicine 2004;16:309-314. [http://dx.doi. org/10.1080/jmf.16.5.309.314]

9. Klingenberg C, Embleton N, Jacobs SE, O'Connell LAF, Kuschel CA. Enteral feeding practices in very preterm infants: an international survey. Arch Dis Child Fetal Neonatal Ed 2012;97:F56-F61. [http://dx.doi.org/10.1136/ F56 adc.2010.204123]

10. Medpages. South Africa - Hospital Depts Neonatal ICU - Total records per region. http:// medpages.co.za (accessed 15 August 2011).

11. Joolay Y, Horn AR, Harrison MC. Therapeutic hypothermia and hypoxic ischaemic encephalopathy: Opinion and practice of paediatricians in South Africa. J Perinat Med 2012;40(4):447-453. [http:// dx.doi.org/10.1515/jpm-2011-0292]

12. Countdown to 2015. Maternal, Newborn and Child Survival - South Africa 2010 report. http://www.countdown2015mnch.org (accessed 25 January 2013.

13. Bradshaw D, Dorrington RE, Laubscher R. Rapid Mortality Surveillance Report 2011. Cape Town: South African Medical Research Council, 2012.

14. Van Goudoever JB, Sulkers ES, Lafeber HN, Sauer PJJ. Short-term growth and substrate use in very low birth weight infants fed formula with different energy contents. Am J Clin Nutr 2000;71:816-821.

15. Singhal A, Cole TJ, Fewtrell M, Deanfield J, Lucas A. Is slower early growth beneficial for longterm cardiovascular health? Circulation 2004;109:1108-1113.[http://dx.doi.org/10.1161/01. CIR.0000118500.23649.DF] 
16. Morley R, Lucas A. Randomized diet in the neonatal period and growth performance until 7.5-8 years of age in preterm children. Am J Clin Nutr 2000;71:822-828.

17. Ehrenkranz RA, Dusick AM, Vohr BR. Growth in the neonatal intensive care unit influences neurodevelopmental and growth outcomes of extremely low birth weight infants. Pediatrics 2006;117:1253-1261. [http://dx.doi. org/10.1542/peds.2005-1368]

18. Vohr BR, Wright LL, Dusick AM, et al. Neonatal Research Network Center differences and outcomes of extremely low birth weight infants. Pediatrics 2004;113:781-789. [http:// dx.doi.org/10.1542/peds.113.4.781]

19. Morgan J, Young L, McGuire W. Slow advancement of enteral feed volumes to prevent necrotising enterocolitis in very low birth weight infants. Cochrane Database of Systematic Reviews 2011, Issue 3. Art. No.: CD001241. [http://dx.doi.org/10.1002/14651858. CD001241.pub3]

20. Rayyis SF, Ambalavanan N, Wright L, Carlo WA. Randomized trial of 'slow' versus 'fast' feeding advancements on the incidence of necrotizing enterocolitis in very low birth weight infants. J Pediatr 1999;134:293-297. [http:// dx.doi.org/10.1016/s0022-3476(99)70452-x]

21. Salhorta A, Ramji S. Slow versus fast enteral feed advancement in very low birth weight infants: A randomized controlled trial. Indian Pediatr 2004;41:435-441.

22. Caple J, Armentrout D, Huseby V, et al. Randomized controlled trial of slow versus rapid feeding volume advancement in preterm infants.
Pediatrics 2004;114:1597-1600. [http://dx.doi. org/10.1542/peds.2004-1232]

23. Krishnamurthy S, Gupta P, Debnath S, Gomber S. Slow versus rapid enteral feeding advancement in preterm newborn infants 1000-1499g: a randomized controlled trial. Acta Paediatr 2010;99:42-46.

24. Sergeyev E, Gebauer C, Knupfer M, Pulzer F, Robel-Tillig E. Enteral feeding volume advancement by using a standardized nutritional regimen in preterm infants $<1750 \mathrm{~g}$ birth weight: a controlled randomized trial. Klin Padiatr 2011;223(1):15-21. [http://dx.doi. org/10.1055/s-0030-1265170]

25. Bombell S, McGuire W. Early trophic feeding for very low birth weight infants. Cochrane Database of Systematic Reviews 2009, Issue 3. Art. No.: CD000504. [http://dx.doi. org/10.1002/14651858.CD000504.pub3]

26. Embleton NE, Pang N, Cooke RJ. Postnatal malnutrition and growth retardation: an inevitable consequence of current recommendations in preterm infants? Pediatrics 2001;107:270-273. [http://dx.doi.org/10.1542/peds.107.2.270]

27. De Boo HA, Cranendonk A, Kulik W, Harding JE, Lafeber HN. Whole body protein turnover and urea production of preterm small for gestational age infants fed fortified human milk or preterm formula. J Pediatr Gastroenterol Nutr 2005;41:81-87.

28. Agostoni C, Buonocore G, Carnielli VP, et al. Enteral nutrient supply for preterm infants: commentary from the European Society of Paediatric Gastroenterology, Hepatology and Nutrition Committee on Nutrition. J Pediatr Gastroenterol Nutr 2010;50:85-91.
29. Kuschel CA, Harding JE. Multicomponent fortified human milk for promoting growth in preterm infants. Cochrane Database of Systematic Reviews 2004, Issue 1. Art. No.: CD000343. [http://dx.doi.org/10.1002/14651858. CD000343.pub2]

30. Doege C, Bauer J. Effect of high volume intake of mother's milk with an individualized supplementation of minerals and protein on early growth of preterm infants $<28$ weeks of gestation. Clin Nutr 2007;26:581-588. [http://dx.doi. org/10.1016/j.clnu.2007.06.002]

31. Schanler RJ, Lau C, Hurst NM, et al Randomized trial of donor human milk versus preterm formula as substitute for mothers' own milk in the feeding of extremely premature infants. Pediatrics 2005;116:400-406. [http:// dx.doi.org/10.1542/peds.2004-1974]

32. Quigley M, Henderson G, Anthony MY, McGuire W. Formula milk versus donor breast milk for feeding preterm infant or low birth weight infants. Cochrane Database of Systematic Reviews 2007, Issue 4. Art. No.: CD002971. [http://dx.doi.org/10.1002/146551858. CD002971.pub2]

33. Masters K. Access to and use of the internet by South African general practitioners. Int J Med Inform 2008;77:778-786. [http://dx.doi. org/10.1016/j.ijmedinf.2008.05.008]

34. Partridge JC. Intensive care for very low birthweight infants in South Africa: a survey of physician attitudes, parent counselling and resuscitation practices. J Trop Pediatr 2005;51:11-16. [http://dx.doi.org/10.1093/ tropej/fmh066] 